\title{
Um comentário sobre o antigo consenso no debate sobre a transformação dos valores em preços de produção
}

\section{Tiago Camarinha Lopes ${ }^{1}$}

Na edição vol. 48.3 da Estudos Econômicos, Lucas e Serrano (2018) retomaram o debate da transformação dos valores em preços de produção com uma tese bem definida: as novas abordagens elaboradas a partir dos anos 1980 para fazer frente ao choque de Sraffa "são problemáticas e, do ponto de vista analítico, não representam uma contribuição positiva ao tema" (p. 525). Assim, defendem o retorno ao antigo consenso deste debate, que se sustenta formalmente em dois pontos referentes ao algoritmo de transformação: primeiro, o de que o objetivo do procedimento da transformação era determinar a taxa geral de lucro a partir dos valores-trabalho e, uma vez conhecida esta taxa, calcular os preços de produção e, segundo, o de que havia sido confirmado que "os desvios dos valores em relação aos preços de produção não se compensam no agregado e, portanto, no caso geral de composições orgânicas diferentes entre os setores é impossível obter simultaneamente as chamadas duas igualdades marxianas - massa de lucro igual à massa de mais-valia, e valor-trabalho da produção bruta igual ao valor (em preço) da produção bruta (também conhecido como "a soma dos preços é igual à soma dos valores")” (p. 526).

De fato, não é possível discordar que as novas abordagens são problemáticas. Também é necessário reconhecer que, do ponto de vista estritamente analítico, tais abordagens têm dificuldade em levar o debate adiante. Contudo, é importante lembrar que o problema da transformação dos

\footnotetext{
1 Professor - Universidade Federal de Goiás (UFG) - Faculdade de Administração, Ciências Contábeis e Ciências Econômicas - Campus Samambaia - Endereço: Rua Samambaia, s/n - Chácaras Califórnia, Goiânia/GO - CEP: 74001-970 - E-mail: tiagocamarinhalopes@gmail.com.

ORCID: https://orcid.org/0000-0002-5907-777X.

Recebido: 17/04/2019. Aceite: 03/12/2019.

Editor Responsável: Rogério Arthmar
}

(c) (i) (\$) Esta obra está licenciada com uma Licença Creative Commons Atribuição-Não Comercial 4.0 Internacional. 
valores em preços de produção não é apenas uma controvérsia analítica. Ela é também expressão da luta política em torno da teoria do valor: dependendo da interpretação que se dê à solução analítica, pode-se tanto aprovar quanto reprovar a teoria do valor trabalho.

O mero retorno ao antigo consenso dos anos 1970 sem uma consideração desse contexto implica fortalecer um tipo de ataque à teoria do valor dos trabalhadores que emergiu assim que a abordagem do excedente dos clássicos foi reabilitada como resultado direto da obra de Sraffa. Criticar as novas abordagens focando apenas no aspecto analítico pode ter efeito colateral indesejado, justamente porque a força delas não está nesta esfera, mas sim no esforço em denunciar a existência de forças políticas que bloqueiam sistematicamente a habilitação de Karl Marx na ciência econômica oficial. No caso do problema da transformação, a genealogia de tais forças remonta a Eugen von Böhm-Bawerk ([1896] 2007), quem originalmente mais explorou a contradição entre valor e preço para "fechar o sistema de Marx".

O retorno ao antigo consenso defendido por Lucas e Serrano (2018) pode levar o leitor equivocadamente a achar (i) que não houve nenhum progresso desde os anos 1970, (ii) que o resultado analítico do antigo consenso está na fronteira da controvérsia e (iii) que a divergência entre os sistemas de Sraffa e Marx possui fundamento real.

O ponto de partida do desentendimento mútuo entre Sraffianos e Marxistas deriva do fato do modelo de Sraffa permitir tanto a reabilitação da teoria clássica do valor trabalho, quanto a renovação fortalecida de uma crítica singular a essa teoria, que já havia sido aventada por Wilhelm Lexis e comentada por Friedrich Engels em 1895 (Engels ([1894] 2004) e Lexis (1895)). De um lado há os que utilizam esse resultado ambíguo para reviver a teoria do valor trabalho e todas as consequências políticas que dela se possa tirar. De outro, há os que a utilizam para desmerecer a teoria do valor trabalho como um apêndice redundante e irrelevante, embora não completamente errado.

Resgatar o antigo consenso sem a adequada consideração desse elemento político significa retroceder à segunda fase do problema da transformação, que foi de Ladislaus von Bortkievicz (1906-1907) até Paul Samuelson (1971) e abrir caminho para anular 50 anos de trabalho em torno do embate que se ergueu a partir do algoritmo borracha de Samuelson. 
Como efeito colateral de uma crítica acertada no que tange à questão estritamente analítica, Lucas e Serrano (2018) acabam desmerecendo o esforço justificado de autores marxistas como Duménil (1983), Foley (1982 e 2000), Lipietz (1982) e Campbell (1997), Wolff, Callari e Roberts (1982) e Moseley (2000). Tal desdenho atinge inclusive a forma mais desenvolvida em trabalho coletivo e popularizada dessa linha, o "Sistema Temporal Único” (TSSI, Temporal Single System Interpretation), construído em uma série de convergências e acúmulos de Freeman (1996), Kliman e McGlone (1999), Campbell (1997), Foley (2000), Duménil e Foley (2006).

Essas abordagens são facilmente identificadas por substituírem sucessivamente as definições de valores-trabalho numa tentativa desesperada de "salvar Marx", num processo interminável de renomeação de conceitos. Certamente, isso não pode ser classificado como contribuição positiva para a controvérsia, a não ser que se lembre daquele componente político que a ronda permanentemente. Nos anos 1970 não havia difusão dos dados referentes ao pensamento e atuação política de Sraffa como se tem hoje. Por essa razão, rebobinar o debate para o passado sem considerar as informações atualmente disponíveis sobre sua práxis, como um economista comunista que sempre teve como referência intelectual última o velho mouro, pode complicar ainda mais a comunicação entre os seguidores de Marx e os de Sraffa.

$\mathrm{Na}$ verdade, essa literatura dos que querem "salvar Marx" do ataque de Sraffa (ou melhor, do ataque daqueles que manuseiam o modelo de Sraffa taticamente contra Marx, por meio do resgate da abordagem do excedente fisiocrata limitado até Ricardo apenas) não tem como objetivo resolver o (falso) problema da transformação e impor um novo entendimento ao mesmo. A função histórica e razão de ser das sucessivas redefinições de valores-trabalho têm outra natureza. O objetivo proposto por estes autores é muito mais modesto e crucial para uma discussão que já não conhece mais sua história nem seu sentido na luta de classes que se desenrola dentro da ciência econômica.

O verdadeiro objetivo dessa corrente da literatura sob ataque de Lucas e Serrano (2018) é colocar o procedimento de Marx como um dos inúmeros métodos à disposição para começar o longo caminho de solução do problema. Segundo essa literatura, o procedimento de Marx não pode ser excluído de antemão, estando, portanto, habilitado a ser um ponto de partida de investigação do problema. A meta não é propor uma solução nova, 
mas defender o começo da leitura da controvérsia pela ótica do próprio Marx, o que necessariamente leva a uma riquíssima contribuição. Afinal, trata-se de um debate extremamente intrincado e longo que remonta às ambiguidades da teoria do valor de Adam Smith.

A TSSI, principal resultado dos avanços da controvérsia das últimas quatro décadas pelo lado Marxista, conseguiu mesmo que tangencialmente expressar que o conflito Marx-Sraffa que subjaz à hegemonia da leitura de Samuelson sobre a transformação dos valores em preços é uma criação artificial, cujo efeito prático é limitar o resgate da Economia Política aos clássicos pré-Marx evitando, assim, a retomada também da Crítica da Economia Política.

Ao destrinchar com detalhes o âmbito analítico de cada uma das abordagens (New Solution, New Interpretation, Reconceitualização Radical, Sistema Único Temporal e a Abordagem Macro Monetária), Lucas e Serrano (2018) acabam dedicando muita atenção a um aspecto que não confere verdadeiramente unidade a esse grupo. O principal elemento que une esses autores é a vontade justa de ir além da abordagem do excedente e dos clássicos em direção a Marx.

A questão é que o "antigo consenso" dos anos 1970, exatamente como o padrão de crítica do "antiquíssimo consenso" de Böhm-Bawerk, tornou-se uma espécie de gatilho para a ideia de que Marx errou na solução do problema da transformação. Desse modo, tal percepção acabou também sendo usada para erguer um muro entre os elementos clássicos que poderiam ser reabilitados (excedente fisiocrata, unidade de análise sistêmica e nacional, abstração orientada para os agregados) e aqueles que não poderiam (exploração da força de trabalho, desigualdade sistêmica e cumulativa do capital, etc.). Desde que a perspectiva de excedente fisiocrático não se ligasse robustamente à teoria do valor trabalho, gerando as conclusões lógicas de exploração desenroladas por Marx até o fim, tudo estaria bem. Trata-se de estratagema que tolera o retorno da abordagem do excedente, mas não das consequências militantes desenvolvidas pelos autores socialistas, incluindo Marx, que bravamente conquistaram a Economia Política de sua época. Contra isso insurge-se corretamente o grupo sob crítica de Lucas e Serrano (2018), que ao se restringirem ao aspecto analítico, acabam induzindo o leitor a achar que não há mérito algum no esforço dessas sucessivas redefinições. 
Se houver acordo sobre isso, então é necessário buscar uma ponte entre os sistemas de Sraffa e Marx. Nessa linha, Bertram Schefold (2016), por exemplo, publicou recentemente um estudo que explica em que sentido o antigo consenso não se sustenta completamente e como a aproximação de Marx é válida e consistente em suas próprias bases. Isso quer dizer que, mesmo analiticamente, não é correto afirmar que as soluções do modelo Sraffiano e do protocolo de transformação sugerido por Marx sejam diferentes a ponto de serem alternativas excludentes para resolver o problema. A partir de minuciosa investigação auxiliada pelos manuscritos de Marx não editados por Engels para a composição do livro 3 do Capital, Schefold $(2016,2019)$ demonstra que a igualdade entre a soma de valores e a de preços fica assegurada em média em um sistema de reprodução econômica cujas matrizes de insumo são aleatórias. Desse modo, a ideia de que a transformação se refere a um processo de distribuição ou apropriação da massa total de valor produzida, como Marx concebia o problema, pode ser rigorosamente defendida em pé de igualdade com as soluções tradicionais do antigo consenso.

Ian Wright (2019), por sua vez, vai mais longe. Ele mostra, com base na tese de separação de Luigi Pasinetti, que a teoria do valor-trabalho, no sentido fisiológico ou naturalista dos clássicos, e a teoria do valor-trabalho, socialmente determinada de Marx, sobrepõem-se, de modo que não há incongruência entre as duas. $\mathrm{O}$ enquadramento da teoria do valor trabalho é possível tanto em um arcabouço a-histórico de consideração do sistema econômico, que apenas descreve os vínculos de transformação da matéria ditados pelos coeficientes técnicos, quanto naquele arcabouço que especifica instituições sociais historicamente datadas.

A contribuição de Wright (2019) reforça uma linha de pesquisa importante que está no núcleo da controvérsia entre os seguidores de Sraffa e Marx. Divergências entre os sistemas de Marx e Sraffa no que tange à teoria do valor se referem às mesmas divergências entre os sistemas da economia política clássica pré-Marx (teoria do valor trabalho incorporado, que naturaliza o processo de criação de valor por meio do dispêndio de músculos, energia, etc.) e a teoria de Marx que, ao desconstruir a naturalização do valor trabalho, constrói ao mesmo tempo uma conceituação sócio-historicamente determinada que engloba a teoria do valor dos socialistas utópicos, mas vai além. 
Logicamente, não pode existir incompatibilidade entre as soluções de Sraffa e de Marx para o problema da transformação, tendo-se presente a relação de complementaridade na qual o sistema de Marx engloba todo o sistema clássico.

Considerando a amplitude da controvérsia, a proposta de retorno ao antigo consenso parece inadequada para conduzir os embates adiante (i) porque houve progresso na controvérsia desde então, visto que as divergências hoje se dão devido às distintas interpretações políticas sobre a solução puramente quantitativa do problema, (ii) porque o resultado analítico do antigo consenso não está na fronteira da controvérsia, mesmo considerando seu âmbito puramente quantitativo como indicam as contribuições de Schefold (2016) e Wright (2019) e, (iii) porque a divergência entre os sistemas de Sraffa e Marx não é grande o suficiente para justificar um posicionamento que, na prática, exclui autores que merecem apoio por desafiar corretamente a ideia de que a solução para o problema da transformação afeta negativamente a teoria de Marx.

Em resumo: defender o retorno ao antigo consenso sem considerar o quadro mais amplo da luta de classes em torno da teoria do valor pode ter efeito colateral danoso de colaborar com o sistemático expurgo político de Marx da oficialidade da ciência econômica e contribuir com a proliferação do neoricardianismo, um fenômeno de vulgarização que em nada se relaciona com o legado de Piero Sraffa.

\section{Referências}

Böhm-Bawerk, E. von (1896 [2007]) Karl Marx and the Close of his System. Auburn, Alabama: Ludwig von Mises Institute.

Campbell, A. (1997). "The transformation problem: A simple presentation of the "new solution." Review of Radical Political Economics 29: 59-69.

Engels, F. (1894 [2004]). Vorwort: Das Kapital. Kritik der Politischen Ökonomie. Dritter Band. Hamburg 1894. In: Marx-Engels-Gesamtausgabe. Zweite Abteilung: "Das Kapital” und Vorarbeiten, Bd. 15. [MEGA, II, 15, Text], Berlin: Akademie Verlag, 2004, 5-23. Prefácio de O Capital - Livro III”.

Foley, Duncan; Duménil, Gérard. 2008. Marxian transformation problem. In: The New Palgrave Dictionary of Economics. Second Edition. Edited by Steven N. Durlauf and Lawrence E. Blume. Palgrave Macmillan, 2008. The New Palgrave Dictionary of Economics Online. Palgrave Macmillan. Acessado em 22/01/2017. doi: $10.1057 / 9780230226203.1052$ 
Foley, D. (1982). The value of money, the value of labor power, and the Marxian transformation problem. Review of Radical Political Economics, 14: 37-49.

Foley, D. (2000). Recent developments in the labor theory of value. Review of Radical Political Economics, 32: 1-39.

Freeman, A. (1996). Price, value and profit - a continuous, general treatment. In: Alan Freeman \& Guglielmo Carchedi (Eds). Marx and Non-Equilibrium Economics. Cheltenham: Edward Elgar: 225-279.

Kliman, A,; McGlone, T. (1999). A temporal single-system interpretation of Marx's value theory. Review of Political Economy, 11: 33-59.

Lexis, W. (1895). The concluding volume of Marx's Capital. The Quarterly Journal of Economics, 10(1):1-33. Lipietz, A. (1982). “The so-called 'transformation problem' revisited.” Journal of Economic Theory 26: 59-88.

Lucas, G. D. e Serrano, F. (2018). Valores-Trabalho através de uma Sucessão de Redefinições: Uma Análise das "Novas Soluções" para o "Problema da Transformação". Estud. Econ. [online]. 2018, vol.48, n.3, pp.525-554.

Moseley, F. (2000). The "New Solution" to the Transformation Problem: a Sympathetic Critique. Review of Radical Political Economics 2: 282-316.

Schefold, B. (2016). Profits equal surplus value on average and the significance of this result for the Marxian theory of accumulation. Cambridge Journal of Economics 2016, 40: 165-199.

Schefold. B. (2019). The transformation of values into prices on the basis of random system revisited. Evolutionary and Institutional Economics Review, vol. 16, 2: 261-302.

Wolff, R., Roberts, B., Callari, A. (1982). Marx's (Not Ricardo's) ‘Transformation Problem': A Radical Reconceptualization. History of Political Economy vol. 14: 564-582

Wright, I. (2019). Marx's transformation problem and Pasinetti's vertically integrated subsystems, Cambridge Journal of Economics vol. 43, Issue 1, 17, pp. 169-186. 